\title{
MOTIVASI MELAKUKAN SELF MONITORING BLOOD GLUCOSE DENGAN DIABETES SELF MANAGEMENT PADA PASIEN DIABETES MELITUS TIPE 2
}

\author{
Gresty Natalia Maria Masi ${ }^{1}$, Yulia $^{2}$, Masfuri $^{3}$ \\ Program Studi Ilmu Keperawatan FK Universitas Sam Ratulangi Manado ${ }^{1}$ \\ Fakultas ilmu Keperawatan, Universitas Indonesia, Kampus UI Depok, 16426, Indonesia' ${ }^{2} 3$ \\ E-mail : ns.grestymasi@gmail.com
}

\begin{abstract}
Abstrak
Kontrol glukosa darah dapat dipertahankan melalui perawatan mandiri. Motivasi melakukan self monitoring blood glucose (SMBG) yang baik dapat meningkatkan diabetes self management pada pasien diabetes melitus tipe 2 . Tujuan penelitian ini adalah untuk mengetahui hubungan motivasi melakukan SMBG dengan diabetes self management pada pasien diabetes melitus tipe 2. Penelitian ini menggunakan metode kuantitatif observasional analitik dengan pendekatan crossectional, melibatkan 96 pasien. Alat ukur yang digunakan berupa kuesioner karakteristik responden, Treatment Self Regulation Questionare, Diabetes Self Management Questionare, Diabetes Knowledge Scale. Hasil penelitian menunjukkan terdapat hubungan yang bermakna antara motivasi melakukan SMBG dengan diabetes self management $(p$ =0,001). Hasil analisis regresi logistik menunjukkan motivasi melakukan SMBG berhubungan dengan didabetes self management setelah dikontrol variabel pengetahuan. Kesimpulan diperlukan perhatian khusus dari perawat untuk meningkatkan motivasi melakukan SMBG pada pasien diabetes melitus tipe 2 dalam self care management.
\end{abstract}

Kata kunci : Motivasi, SMBG, diabetes self management

\begin{abstract}
Glycemic control could be maintained through diabetes self-management. Motivation to perform self-monitoring blood glucose (SMBG) could improve diabetes self-management in type 2 diabetes mellitus patients. The purpose of this study was to explore the relationship between motivation to perform SMBG and diabetes self-management in patients with type 2 diabetes mellitus. This study applied quantitative method with a cross sectional approach, involving 96 patients. The Instruments used were questionnaires for respondent characteristics, Treatment Self-Regulation Questionnaire, Diabetes Self Management Questionnaire and Diabetes Knowledge Scale. The results show that there was a significant relationship between motivation to perform SMBG and diabetes self-management ( $\mathrm{p}=0,001)$. Results of logistic regression analysis showed that motivation to perform SMBG is associated with diabetes self-management after controlled by knowledge variable. In conclusion it is a necessarily for nurses to provide attention to increase motivation to perform SMBG in patients with type 2 diabetes mellitus as part of self care management.
\end{abstract}

Keywords: Motivation, SMBG, diabetes self management 


\section{PENDAHULUAN}

Diabetes melitus merupakan penyakit kronis yang kompleks dan menjadi salah satu masalah kesehatan terbesar dunia dengan proyeksi peningkatan kasus baru yang terus meningkat setiap tahun (ADA, 2014; Scobie, 2007). Jumlah penderita diabetes melitus tahun 2013 di dunia sebanyak 347 juta orang (WHO, 2013). Data dari International Diabetes Federation (IDF) menunjukkan total kasus diabetes melitus pada tahun 2013 adalah sekitar 382 juta orang dan diperkirakan pada tahun 2035 akan terjadi peningkatan sebesar $50 \%$ menjadi 592 juta orang (IDF, 2014).

Diabetes melitus tidak bisa disembuhkan (deWit \& Kumagai, 2013), namun diabetes dapat dikendalikan dengan mengatur kadar glukosa darah dalam rentang normal (deWit \& Kumagai, 2013; Jones, 2014). Oleh karena diabetes melitus merupakan penyakit kronik dengan kompleksitas pengelolaannya, maka diperlukan partisipasi aktif dari pasien melalui self management (Heinrich, Schaper \& Vries, 2010). Manajemen diri diabetes sangat penting karena penerapan prilaku gaya hidup sehat akan menghasilkan kontrol glikemik yang optimal dan dapat meminimalkan atau mencegah komplikasi diabetes baik hiperglikemia maupun hipoglikemia (Norris et al. 2001; Sousa, Zauszniewski, Musil, Harga Lea, \& Davis, 2005).
Kunci dari manajemen diabetes melitus adalah menjaga kadar glukosa darah sedekat mungkin ke nilai normal atau dengan jarak target yang disepakati oleh pasien dengan penyedia pelayanan (Black \& Hawks, 2009). Self monitoring blood glucose (SMBG) dapat mendorong pasien diabetes dalam mengelola diabetesnya berdasarkan kadar glukosa darahnya (IDF, 2014). Hasil penelitian menunjukan terdapat hubungan yang signifikan antara monitoring glukosa darah dengan satatus glikemik, (Aghili, Khamseh, Malek, Yarahmadi, \& Farshchi, 2012). Penelitian yang dilakukan terhadap pasien diabetes melitus tipe 2 dengan terapi obat hiperglikemi oral menunjukan $89 \%$ melakukan SMBG dan jarang mengalami hipoglikemia oleh karena mereka menyesuaikan dosis obat anti hiperglikemi oral dengan hasil SMBG (Agborsangaya et al. 2013).

Kenyataannya beberapa penelitian menunjukkan hasil yang bertentangan dimana tidak terdapat hubungan antara SMBG dengan kontrol glikemik pada pasien diabetes melitus (Kenya, lebron, Arrechea, \& Li, 2013). Efek klinis karena SMBG hanya bisa didapatkan ketika pasien menyesuaikan gaya hidup, diet, olahraga, atau terapi farmakologi diabetes mereka berdasarkan hasil SMBG (Agborsangaya et al., 2013; Brackney, 2010). Kenya, Lebron, Arrechea dan Li (2013) menyatakan dalam hasil penelitiannya banyak pasien tidak mengambil tindakan dalam 
menanggapi hasil pembacaan glukometer sehingga dibanyak populasi praktek SMBG tidak berhubungan dengan glikemik kontrol. Hasil penelitian lainnya menjelaskan bahwa praktisi mengharapkan pasien dapat menggunakan hasil SMBG untuk mengubah perilaku kesehatan mereka (Peel et al., 2007).

Untuk merubah prilaku seseorang, dibutuhkan motivasi yang mendasari perubahan prilaku tersebut (Guay et al dalam Lai 2011). Motivasi secara umum berarti sesuatu yang mendorong untuk berbuat atau bereaksi (Sunaryo, 2013). Dari hasil penelitian yang dijelaskan diatas menunjukan apabila pasien diabetes melitus punya motivasi untuk melakukan perubahan diri dalam manajemen diabetesnya melalui hasil pengontrolan glukosa darah mandiri maka mereka akan menggunakan hasil pengontrolan glukosa darah tersebut sebagai penanda apa yang harus mereka lakukan seperti mengontrol diet, olah raga dan obatobatanya untuk mencapai kontrol glikemi yang baik.

\section{METODE PENELITIAN}

Desain analitik observasional dengan pendekatan studi cross sectional, dilakukan pada 96 pasien diabetes melitus tipe 2 untuk mengetahui motivasi melakukan SMBG dengan diabetes self management dengan menggunakan kuesioner karakteristik demografi responden, Treatment Self Regulation Questionare (TSRQ), Diabetes

\section{Self Management Questionare (DSMQ),} Diabetes Knowledge Scale (DKS). Pengambilan data dilakukan secara bersamaan setelah pasien menyetujui untuk menjadi responden penelitian. Pengolahan data dalam penelitian ini menggunakan aplikasi komputer. Dalam proses pengambilan data, peneliti menerapkan prisnsip-prinsip etika penelitian keperawatan untuk menghindarkan responden terhadap hal-hal yang dapat merugikan.

\section{HASIL}

\section{Analisis univariat}

Analisis univariat (Tabel 1). Responden dalam penelitian ini sebagian besar berumur $\geq 56$ tahun yaitu $49(51.0 \%)$ responden, sebagian besar berjenis kelamin perempuan 54 (56.3\%) responden, sebagian besar menderita diabetes melitus $\geq 9$ tahun 75 (78.1\%) responden, sebagian besar responden berpendidikan rendah 67 (69.8\%), sebagian besar responden memiliki pekerjaan 73 (76.0\%), sebagian besar memiliki pendapatan tinggi $63(65.6 \%)$. Selain itu juga sebagian besar responden dalam penelitian ini memiliki pengetahuan yang baik tentang diabetes melitus yakni $66(68.8 \%)$ responden, dan responden yang memiliki motivasi melakukan SMBG yang baik 69 (71.9\%) responden, serta sebagian besar 65 (67.7\%) responden memiliki diabetes self management yang adekuat. 
dan motivasi melakukan SMBG memiliki hubungan yang signifikan ( $p$ value $<0.05$ ).

Tabel 1. Distribusi Responden Berdasarkan Umur, Jenis Kelamin, Lama Menderita, Tingkat Pendidikan, Pekerjaan, Pendapatan dan Pengetahuan Pasien Diabetes Melitus Tipe 2 Mei - Juni 2015 ( $\mathrm{n}=96)$

\begin{tabular}{llcc}
\hline Variabel & Kategorik & $\begin{array}{c}\text { Jumlah } \\
\text { Umur }\end{array}$ & $\begin{array}{c}\text { Persentase } \\
(\%)\end{array}$ \\
& $\geq 56$ tahun & 49 & 51,0 \\
Jenis & L 56 tahun & 47 & 49,0 \\
Kelamin & Perempuan & 54 & 56,3 \\
Lama & $<9$ tahun & 21 & 21,9 \\
menderita & $\geq 9$ tahun & 75 & 78,1 \\
Pendidikan & Rendah & 67 & 69,8 \\
& Tinggi & 29 & 30,2 \\
Pekerjaan & Tidak & 23 & 24,0 \\
& Bekerja & & \\
Pendapatan & Rekerja & 73 & 76,0 \\
& Tinggi & 33 & 34,4 \\
Pengetahuan & Kurang & 30 & 65,6 \\
& Baik & 66 & 68,3 \\
Motivasi & Kurang & 27 & 28,1 \\
melakukan & Baik & 69 & 71,9 \\
SMBG & & & \\
Diabetes self & Inadekuat & 29 & 30,2 \\
management & Adekuat & 67 & 69,8 \\
\hline
\end{tabular}

\section{Analisis bivariat}

Analisis bivariat (tabel 2) dalam penelitian ini tidak terdapat hubungan signifikan antara jenis kelamin, tingkat pendidikan, pekerjaan dengan diabetes self management ( $p$ value >0.05). Pengetahuan responden tentang diabetes melitus, umur, lama menderita, pendapatan

Tabel 2. Hasil Analisis Hubungan Umur, Jenis Kelamin, Lama Menderita, Tingkat Pendidikan, Pekerjaan, Pendapatan, Pengetahuan dan motivasi melakukan SMBG dengan Diabetes Self Management Pada Pasien Diabetes Melitus tipe 2, Bulan Mei Juni $2015(\mathrm{n}=96)$

\begin{tabular}{|c|c|c|c|c|}
\hline \multirow{3}{*}{ Variabel } & \multirow{2}{*}{\multicolumn{2}{|c|}{$\begin{array}{c}\text { Diabetes } \\
\text { Self } \\
\text { management }\end{array}$}} & \multirow{3}{*}{$\begin{array}{c}\text { OR } \\
(95 \% \mathrm{CI})\end{array}$} & \multirow{3}{*}{$\begin{array}{c}\mathrm{p} \\
\text { value }\end{array}$} \\
\hline & & & & \\
\hline & $\begin{array}{c}\mathrm{n} \\
(96)\end{array}$ & $\%$ & & \\
\hline \multicolumn{5}{|l|}{ Umur } \\
\hline$\geq 56$ th & 49 & 51,0 & 4,656 & 0,003 \\
\hline$<56$ th & 47 & 49,0 & $(1,74-12,41)$ & \\
\hline \multicolumn{5}{|l|}{ Jenis Kelamin } \\
\hline Laki-laki & 42 & 43,8 & 0,710 & 0,595 \\
\hline Perempuan & 54 & 56,2 & $(0,29-1,72)$ & \\
\hline \multicolumn{5}{|c|}{ Lama Menderita } \\
\hline$<9$ th & 21 & 21,9 & 4,549 & 0,006 \\
\hline$\geq 9$ th & 75 & 78,1 & $(1,64-12,60)$ & \\
\hline \multicolumn{5}{|l|}{ Pendidikan } \\
\hline Rendah & 67 & 69,8 & 1,198 & 0,900 \\
\hline Tinggi & 29 & 30,2 & $(0,45-3,14)$ & \\
\hline \multicolumn{5}{|l|}{ Pekerjaan } \\
\hline Tidak bekerja & 23 & 24,0 & 1,704 & 0,419 \\
\hline Bekerja & 73 & 76,0 & $(0,63-4,55)$ & \\
\hline \multicolumn{5}{|l|}{ Pendapatan } \\
\hline Rendah & 33 & 34,4 & 3,620 & 0,010 \\
\hline Tinggi & 63 & 65,6 & $(1,44-9,04)$ & \\
\hline \multicolumn{5}{|l|}{ Pengetahuan } \\
\hline Kurang & 30 & 31,3 & 3,714 & 0,006 \\
\hline Baik & 66 & 68,7 & $(1,46-9,39)$ & \\
\hline \multicolumn{5}{|l|}{ Motivasi } \\
\hline Melakukan & & & & \\
\hline$S M B G$ & & & & \\
\hline
\end{tabular}




$\begin{array}{lllcc}\text { Kurang } & 27 & 28,1 & 48,06 & 0,009 \\ \text { Baik } & 69 & 71,9 & (2,03-159,67) & \end{array}$

*signifikan $\alpha 0.05$

\section{Analisis Multivariat}

Tabel 5.8

Hasil Pemodelan Akhir Variabel Utama dan Variabel Counfounding dengan Diabetes Self Management Pada Pasien Diabetes Melitus Tipe 2 di RSUP Prof. dr. R. D. Kandou Manado Bulan Mei - Juni 2015 ( $\mathrm{n=96)}$

\begin{tabular}{lccccc}
\hline Variabel & B & Wald & $p$ value & OR & CI 95\% \\
\hline Motivasi melakukan SMBG: & 2,783 & 22,143 & 0,001 & 16,168 & $5,073-51,534$ \\
Pengetahuan: & 0,496 & 0,687 & 0,407 & 1,642 & $0,508-5,307$ \\
Constant & $-2,298$ & 11,017 & 0,001 & 0,100 & \\
& & & & &
\end{tabular}

Pengetahuan merupakan variabel konfonding yang ditunjukkan dengan perubahan nilai OR variabel utama (motivasi melakukan SMBG) saat variabel pengetahuan dikeluarkan. Adapun pemodelan akhir dalam analisis multivariat (tabel 3), responden yang memiliki motivasi melakukan SMBG yang baik berpeluang sebanyak 16,168 kali menunjukkan diabetes self management yang adekuat dibandingkan dengan responden yang memiliki motivasi melakukan SMBG kurang, setelah dikontrol oleh variabel pengetahuan (95\% CI : 5,073;51,534).

\section{PEMBAHASAN}

Dalam penelitian ini terdapat hubungan antara umur dengan diabetes self management pada pasien diabetes melitus tipe 2. Responden dalam penelitian ini berumur antara 37-65 tahun, dengan kategori umur $\geq 56$ tahun dan $<$ 56 tahun. Responden dengan umur $<56$ tahun lebih berpeluang menunjukkan diabetes self management yang adekuat. Penelitian Huang et al. (2014) pada pasien diabetes melitus tipe 2 berumur antara 60-80 tahun menunjukkan responden dengan umur yang semakin tua memiliki prilaku self management yang buruk. Ini disebabkan karena orang dewasa diatas 65 tahun dengan penyakit tertentu umumnya mengalami gangguan dalam proses belajar dan memori termasuk didalamnya pasien diabetes melitus, dimana pasien diabetes melitus mengalami perubahan fungsional yang terjadi disistem saraf pusat sehingga pasien diabetes cenderung rentan terhadap proses belajar (Asimakopoulou \& Hampson, 2002). Responden dalam penelitian ini memiliki diabetes self management yang adekuat kemungkinan disebabkan karena umur responden $<65$ tahun, diamana pada umur $<$ 65 tahun secara fisik dan kognitif dapat 
menjalani proses belajar dan memori (Kozier et al., 2010).

Tidak terdapat hubungan antara jenis kelamin dengan diabetes self management. Responden dalam penelitian ini mayoritas berjenis kelamin perempuan dan menunjukkan kemampuan melakukan diabetes self management yang adekuat dibandingkan lakilaki. Hal ini disebabkan karena perempuan lebih muda melakukan manajemen diabetes dalam kehidupan sehari-hari seperti dalam pembatasan makanan yang disarankan, perempuan juga banyak mencari informasi dalam interaksi sosial, sedangkan laki-laki kurang teliti dalam praktek (Mathew, Gucciardi, De-Melo \& Barata, 2012).

Terdapat hubungan antara lama menderita dengan diabetes self management. Lama menderita diabetes melitus berhubungan dengan ketrampilan pasien dalam melakukan pengelolaan diabetes melitus. Pengalaman hidup yang lama dengan penyakit kronis dapat memberikan petunjuk yang berarti bagi individu dalam hal pengelolaan ketidaknyamanan emosional dan fisik, oleh karena itu penting bagi pasien untuk mengenali pola tertentu dari koping yang digunakan (Lou et al, 2015).

Tingkat pendidikan tidak berhubungan dengan diabetes self management. Hal ini didukung oleh hasil penelitian Mahfouz \& Awadalla
(2011) yang menyatakan bahwa tidak terdapat hubungan antara tingkat pendidikan dengan diabetes self management. Tingkat pendidikan dikaitkan dengan kemampuan seseorang dalam pemahaman akan penyakitnya, Individu yang berpendidikan tinggi lebih mampu menerima dan mempertahankan pengetahuan (Huang et al. 2014). Dalam penelitian ini responden dengan pendidikan tinggi dan rendah dapat menunjukkan diabetes self management yang adekuat, hal ini disebabkan karena sebagian besar responden telah menderita diabetes melitus $>9$ tahun, sehingga mereka memiliki pengalaman dalam mengelola penyakitnya.

Pekerjaan dan diabetes self management tidak memiliki hubungan. Pekerjaan dihubungkan dengan kemampuan pengelolaan diabetes secara mandiri. Responden yang masih aktif dalam bekerja lebih sibuk dan menghabiskan banyak waktu serta aktif dalam interaksi sosial dan menghabiskan sedikit waktu untuk mengelola penyakit mereka (Huang et al. 2014). Dalam penelitian ini sebagian besar responden bekerja sebagai pensiunan PNS yang dihubungkan dengan umur responden, sehingga responden memiliki waktu yang cukup dalam pengelolaan diabetes melitusnya.

Pendapatan responden berhubungan dengan diabetes self management. Hasil penelitian ini didukung oleh penelitian yang dilakuakan oleh 
Luo et al. (2015), dimana terdapat hubungan yang positif antara pendapatan dengan diabetes self management pada pasien diabetes melitus tipe 2 , hasil penelitian menunjukkan bahwa responden dengan pendapatan tinggi menunjukkan diabetes self management yang adekuat. Hal ini dikarenakan pengelolaan diabetes melitus terdiri dari beberapa hal diantaranya obat-obatan yang harus digunakan setiap hari, sehingga pasien harus memiliki dana yang cukup untuk memenuhinya. Akan tetapi responden dalam penelitian ini semuanya adalah peserta BPJS Kesehatan, sehingga dalam pemenuhan obat-obatan serta penggunaan pelayanan kesehatan diperoleh secara gratis.

Dalam penelitian ini pengetahuan berhubungan dengan diabetes self management, responden yang memiliki pengetahuan yang baik tentang diabetes melitus cenderung memiliki diabetes self management yang adekuat. Pengetahuan pasien tentang diabetes melitus sangat mempengaruhi prilaku kesehatan yang mereka jalankan, hasil penelitian yang dilakukan oleh Hendriks \& Rademarkers (2014) menunjukkan bahwa responden yang memiliki pengetahuan diabetes secara umum menunjukkan prilaku aktivitas fisik (olah raga) yang tinggi. Pengetahuan merupakan kepercayaan yang diperoleh melalui pembelajaran dan pengalaman seseorang yang mempengaruhi prilaku, selain itu pengetahuan juga memberikan arahan pada hidup seseorang dalam membuat suatu tujuan, mengantisipasi dan berespon terhadap suatu hal (Hunt, 2003). Dalam penelitian ini pengetahuan responden lebih dihubungkan dengan lamanya mereka menderita diabetes melitus, mereka sering mendapatkan informasi dan pengalaman sehingga meningkatkan pengetahuan mereka.

Terdapat hubungan yang bermakna antara motivasi melakukan SMBG dengan diabetes self management. Responden memiliki motivasi intrinsik yang melatarbelakangi perubahan prilaku mereka dalam pengelolaan diabetes melitusnya. Hasil penelitian ini mendukung hasil penelitian Brackney (2010) dimana apabila pasien memiliki motivasi yang baik dalam melakukan SMBG, maka mereka akan menggunakan hasil pengontrolan gula darah mereka tersebut sebagai acuan dalam melakukan diabetes self management mereka, baik dalam pemilihan makanan, obat-obatan, olah raga dan penggunaan fasilitas kesehatan untuk memeriksakan kondisi kesehatan mereka.

Motivasi adalah alasan yang mendasari terjadinya prilaku dan merupakan kumpulan kepercayaan, persepsi, nilai, perhatian, tindakan yang semuanya saling berhubungan yang ditandai dengan kesediaan dan kemauan (Lai, 2011). Motivasi juga merupakan kekuatan yang dapat menggerakan seseorang dalam beraktivitas dan mempertahankan 
prilaku atau melakukan suatu perubahan (Butler, 2002). Penelitian (Brackney, 2010) menunjukkan bahwa pasien diabetes melitus tipe 2 melakukan perubahan prilaku setelah pemantauan gula darah secara mandiri, disebabkan karena adanya kebulatan tekat yang timbul dari kata hati mereka karena mereka takut akan komplikasi (akibat) dari diabetes melitus yang tidak terkontrol (Brackney, 2010).

Diabetes self management adalah aktifitas yang kompleks termasuk kemampuan dalam mengontrol suatu kondisi, diabetes melitus merupakan penyakit kronis yang memerlukan perawatan berkelanjutan serta self management yang baik untuk mencegah komplikasi akut dan mengurangi komplikasi jangka panjang (Metrig, 2007). Salah satu upaya yang dilakukan untuk mendukung self management adalah dengan edukasi sebagai hal penting dalam manajemen diabetes dan bagian dari cronic care model. Edukasi tidak hanya mencakup informasi tentang penyakit yang spesifik, namun berupa intervensi yang sistematis yang melibatkan partisipasi aktif dari pasien sehingga pasien dapat berperan aktif dalam pengelolaan perawatan diri sendiri melalui pemecahan masalah dan penetapan tujuan yang dapat difasilitasi dengan penggunaan tehnik motivasi (Goldenberg et al, 2013).

\section{Kesimpulan}

Penelitian ini memberikan informasi bahwa untuk menghasilkan diabetes self management yang adekuat pada pasien diabetes melitus, maka diperlukan motivasi yang baik dari pasien baik motivasi intrinsik, maupun motivasi ekstrinsik. Selain itu juga pentingnya pemahaman pasien tentang penyakinya juga mempengaruhi prilaku diabetes self management pasien. Untuk meningkatkan motivasi, pemahaman (pengetahuan) dan diabetes self management pasien diabetes melitus dapat dilakuakan dengan edukasi. Sehingga sangat diperlukan kerja sama yang baik antara pasien dan petugas kesehatan.

\section{Ucapan Terima Kasih}

Ucapan terima kasih disampaikan kepada responden yang telah berpartisipasi dalam penelitian ini, serta Pimpinan dan Karyawan Rumah Sakit tempat penelitian dilaksanakan.

\section{DAFTAR PUSTAKA}

ADA (2014). Standards of medical care in diabetes-2014. Diabetes Care, 37(SUPPL.1), 14-80. doi.org/10.2337/dc14-S014

Agborsangaya, C. B., Gee, M. E., Johnson, S. T., Dunbar, P., Langlois, M.-F., Leiter, L. a, ... Johnson, J. a. (2013). Determinants of lifestyle behavior in type 2 diabetes: results of the 2011 cross-sectional survey on living with chronic diseases in Canada. BMC Public Health, 13(451). doi.org/10.1186/1471-2458-13-451

Aghili, R., Khamseh, M. E., Malek, M., Yarahmadi, S., \& Farshchi, A. (2012). Structured self monitoring of blood glucose in Iranian people with type 2 diabetes; A cost consequence analysis. DARU Journal of Pharmaceutical 
Sciences, 20(1), 32. doi.org/10.1186/2008-2231-20-32

Asimakopoulou, K., \& Hampson, E. S. (2002). Cognitive functioning and selfmanagement in older people with diabetes. Diabetes spectrum. 15(2). Doi. 10.2337/diaspect.15.2.1.16

Black, J. M., \& Hawks, J. H. (2009). Medical surgical nursing clinical management for positive outcome. eighth edition, Elsevier, St. Louis positive outcome, eighth edition, Elsevier, St. Louis.

Brackney. E. D. L. (2010). Knowing Where I Am At \| The Experience of Self Monitoring Blood Glucose for People with Non-Insulin-Requiring Type 2 Diabetes A dissertation presented to the faculty of the Department of Nursing East Tennessee State University In partial fulfillment of. www.searchproquest.com

Butler. A. H. (2002). Motivation: The role in diabetes self management in older adult. UMI. www. searchproquest.com

deWit, S. C., \& Kumagai, C. (2013). Medicalsurgical Nursing; consepts \& practice.

St. Louis, Elsevier.

Goldenberg., \& Punthakee. (2013). Definition, Classification and Diagnosis of Diabetes, Prediabetes and Metabolic Syndrome. Canadian diabetes association clinical practice guidelines expert committee. Canadian Journal of Diabetes, Elsevier.

Heinrich, E., Schaper, N. C., Vries, N. K. De. (2010). Self-management interventions for type 2 diabetes : a systematic review. EDN Autumn 7(2). Doi.10.1002/edn.160

Hendriks. M \& Redmarkers. J (2014). relationship between patient activation, sisease-spesific knowledge and health outcomes among people with diabetes; a survey study. BMC Health Service Research. 14:393, DOI: 10.1186/14726963-14-393

Huang. M., Zhao. R., Li. S., Jiang. X. (2014). Self-Management Behavior in Patients with Type 2 Diabetes : A Cross-Sectional Survey in Western Urban China. PLOS One, Vol. 9 (4).

Hunt. P. D (2003). The concept of knowledge and how to measure it. Journal of
Intellectual Capital, 4(1). 100-113. Doi 10.1108/14691930310455414.

International Diabetes Federation (IDF). (2014). Diabetes facts and figures. http://www.idf.org/worlddiabetesday/too lkit/gp/facts-figures

Jones (2014). Is Marital status a determinant of self monitoring blood glucose? A Thesis presented in partial fulfillment of requirements for the degree of Master of Science in the Department of Nutrition and Hospitality Management The University of Mississippi. www.searchingproquest.

Kenya, S., Lebron, C., Reyes Arrechea, E., \& Li, H. (2013). Glucometer use and glycemic control among Hispanic patients with diabetes in southern Florida. Clinical Therapeutics, 36(4), 485-493. doi.org/10.1016/j.clinthera.2013.12.009

Kozier, B., Erb, G., Berman, A., Snyder, J. S. (2010). Buku ajar fundamental keperawatan: konsep, proses dan praktik. Editor Dwi Widiarti. Jakarta. EGC.

Lai, E. R. (2011). Metacognition : A Literature Review Research Report. Research Reports, (April), 41. Retrieved from http://www.datec.org.uk

Lou. X., Liu. T., Yuan. X., Ge. S., Yang. J., Li. Ch., Sun. W. (2015). Factor influencing self-management in Chinese adults with type 2 diabetes : A systematic review and meta-analisis. International Journal of Environ.Research and Public Health, Vol 12, 11304-11327. DOI: 10.3390/ijerph120911034

Mathew. R., Gucciardi, E., De-Melo, M., Barata, P. (2012). Self Management experiences among men and women with type 2 diabetes mellitus: a qualitative analysis. Biomedcentral Family Practice 13(122). 1-12. Doi.10.1186/1471-229613-122

Mertig. G. R. (2007). The Nurse's guide to teaching diabetes self-management. Springer Publication company. New York.

Noris, N. L., Lau, J., Smith, J. S., Schmid, H. C., Engelgau, M. M. (2001). Self 
management education for adults with type 2 diabetes. Diabetes care 25(7). 1159-1171.

Peel, E., Douglas, M., \& Lawton, J. (2007). Self monitoring of blood glucose in type 2 diabetes : longitudinal qualitative study of patients perspectives. BMJ. 335 (7618).493.

Doi.10.1136/bmj.39302.444572.DE

Sousa V.D., Zauszniewski J.A., Musil. C.M. (2005). Demographic differences of adults with diabetes mellitus - a cross-sectional study. Online Brazilian Journal of Nursing

Scobie. N. I. (2007). Atlas of Diabetes mellitus. third edition. Informa healthcare. USA

Sunaryo (2013). Psikologi untuk keperawatan edisi 2. Editor Barrarah Bariid. Jakarta. EGC

WHO (2013). 10 fact about diabetes. http://www.who.int/features/factfiles/diab etes/facts. 